\title{
The requirement for bioscience knowledge in medical education
}

\section{Geoffrey J McColl MEd, PhD, FRACP Professor \\ Justin Bilszta BAppSci(Hons), PhD, GradCertUniTeach Senior Lecture \\ Stephen Harrap MB BS, PhD, FRACP Professor \\ 1 Medical Education Unit University of Melbourne Melbourne, VIC \\ 2 Department of \\ Physiology, University of Melbourne Melbourne, VIC \\ gimccoll@ \\ unimelb.edu.au}

doi: 10.5694/mjall.10474

An abridged version of this article appeared in the printed Journal

Series Guest Editor

Jennifer J Conn FRACP, MClinEd, BSc(Hons)
$+$ ormal scholarship in the biosciences first became part of medical training in the second half of the 19th century, when medical apprenticeship and learning at the bedside was replaced by the collegiate system of undergraduate training in Germany and France. Teaching and learning in the sciences - physics, chemistry and biology - preceded and then was interspersed with clinical training. ${ }^{1}$ This structure is still visible in 21 st century medical education.

Here, we explore the arguments surrounding the need for bioscience knowledge in medical education, and focus on two critical questions: does bioscience learning assist in educating medical students to become competent doctors, and, if so, what are the most effective teaching and learning methods to facilitate this outcome?

\section{What are the core bioscience disciplines?}

Traditionally, the biosciences included anatomy (and embryology), physiology, biochemistry, microbiology and pathology. With the expansion of medical knowledge in the 20th century, other disciplines, such as pharmacology, immunology, neuroscience and genetics, have gained equal importance. Knowledge of medical ethics, communication, population health and the social sciences has also been recognised as important for developing clinical expertise, ${ }^{2}$ but there is debate about whether these disciplines should be regarded as belonging to the core biosciences. We will focus on the "traditional" bioscience disciplines.

\section{The biosciences in modern medical programs}

In 1910, the Carnegie Foundation commissioned a review of medical education in the United States and Canada. The resulting Flexner report was influenced by European ideas about medical education and recommended that medical school programs consist of 2 years of university-based bioscience instruction, followed by 2 years of clinical experience in hospital settings. ${ }^{3}$ The report fostered a model of scientific study of the core bioscience disciplines as the foundation of medical school education. The effect of these reforms was to separate academic and clinical environments, so that students did not see patients until completion of the preclinical basic science years. This became the model for medical schools in North America, the United Kingdom and Australia, for a large part of the 20th century.

The next major shift in bioscience education in medical school programs came in the late 1950s, with the move to more integrated and self-directed approaches to learning.

\section{Summar \\ - The recent 100-year anniversary of the Flexner review and the release of the Australian Medical Education Study have stimulated vigorous debate about the role of bioscience knowledge in medical education. \\ - Two critical questions define debate in this area: does bioscience learning assist in educating medical students to become competent doctors, and, if so, what are the most effective teaching and learning methods to facilitate this outcome? \\ - There is tacit acceptance that specific bioscience knowledge is critical for the development of clinical expertise; however, there are few empirical data to support this notion.}

- Two differing theories have been proposed to describe the role of bioscience learning in the development of clinical reasoning skills - the "two-worlds" model and the "encapsulation" model. A series of studies provides support for the encapsulation model.

- Some medical programs are now integrating bioscience teaching into the clinical years of the course. Evidence of the effectiveness of this on outcomes, such as improved clinical reasoning, is inconclusive.

An organ-based program at Case Western Reserve University (Cleveland, USA) merged the teaching of basic science and clinical knowledge, and was closely followed by the development of problem-based learning (PBL) at McMaster University (Ontario, Canada) ${ }^{1}$ As well as providing a framework for applying bioscience and clinical knowledge to actual patient problems, the PBL model promoted critical analysis of information and encouraged students' active participation in collaborative small groups. PBL became the mainstay of medical education in the latter part of the 20th century.

With the recent 100-year anniversary of the Flexner report and numerous studies evaluating the effectiveness of PBL, there has been vigorous debate about the role of bioscience teaching and learning in medical school programs. ${ }^{1,2}$ In Australia, this debate has been fuelled by the 2008 Australian Medical Education Study (AMES), which evaluated critical educational factors contributing to the outcomes of undergraduate medical education in Australia. ${ }^{4}$ The AMES specifically highlighted the variation across Australia in the amount, type and method of bioscience teaching and learning within medical school programs. There was concern that the depth of bioscience knowledge needed for acquiring clinical expertise was not clearly defined in most medical programs, and that outcomes did not appear to align well with stakeholders' expectations at the vocational level of training. 
Does bioscience learning develop clinical expertise?

Several plausible mechanisms by which bioscience learning in medical programs might assist in developing clinical expertise have been proposed (Box 1).

\section{Building clinical competence}

The proposition that instruction in the biosciences makes it easier to acquire clinical knowledge and skills has a high degree of face validity, but there are few empirical data to support it. One study demonstrated the role of bioscience knowledge in identifying oral and maxillofacial abnormalities. ${ }^{5}$ Dentistry students taught to identify pathophysiological features using basic bioscience performed better on immediate cued-recall tests than students taught using a structured algorithm or a list of clinical features. Compared with students who simply memorised the list of features, those with basic science knowledge better understood why certain pathophysiological features occurred, and the relationship of these features to facial abnormalities.

Despite the lack of published studies, the concept that formal instruction in bioscience underpins the development of specific clinical expertise is widely accepted by academic and clinical educators. The critical issue is how much bioscience knowledge is the minimum required for all doctors (to be included in entry-to-practice medical programs) and how much is required for developing specialised expertise (and can be deferred until postgraduate vocational programs). Opinion is divided between, and even within, disciplines over this issue, and is best illustrated by the vigorous debate in the surgical community about the amount of anatomy teaching needed in contemporary medical programs. ${ }^{6}$

A recent report by the Association of American Colleges and the Howard Hughes Medical Institute describes an attempt to define the breadth and depth of bioscience learning required in entry-to-practice medical programs through a consensus of US experts. ${ }^{7}$ The report outlines the competencies and learning objectives necessary for bioscience teaching and learning in premedical and medical programs. The recommendations emphasise the importance of traditional bioscience disciplines but, contentiously, do not mention a working knowledge of anatomy as being a core proficiency. As yet, there are no publications describing benchmarking by medical schools in the US, or indeed elsewhere, against the standards set out in the report.

\section{Enhancing diagnostic reasoning}

The mechanism most widely discussed in the research literature by which bioscience knowledge might develop clinical expertise concerns diagnostic reasoning. This cognitive process has been investigated over the past few decades, and two differing theories have been proposed to describe the role of bioscience learning in the development of clinical reasoning skills - the "two-worlds" model $^{8}$ and the "encapsulation" model ${ }^{9}$ (Box 2).

Proponents of the two-worlds model argue that experienced doctors separate their bioscience knowledge from their clinical knowledge to effectively create two worlds that only minimally interact during the reasoning process. ${ }^{8}$ The
1 The importance of bioscience knowledge for developing clinical competence Bioscience knowledge:

- explains the biological basis of health and disease and provides a framework for learning

- assists in understanding medical research and advances in aetiology and treatment

- allows concepts in health and disease to be explained to patients and other health professionals

- makes it easier to counter irrational thinking about health, disease and medical treatment

- confirms the biological plausibility of disease if specific clinical information is missing or unclear, thus allowing clinicians to optimise diagnosis, investigation and illness management

- provides a scaffold for exploratory problem solving using a combination of formal education, self-education and experience

rationale is that expert clinicians show little tendency to use basic science when describing patient presentations, instead relying on clinical knowledge, associations and classifications to formulate solutions to diagnostic problems. $8,10,11$

In contrast, the encapsulation model is built on the premise that bioscience knowledge is required to build the foundations of clinical knowledge networks for diagnostic reasoning. ${ }^{9}$ For novice medical students, patient presentations are characterised using detailed bioscience knowledge that is causal in nature and describes disease processes in terms of pathophysiological function. This knowledge gradually becomes integrated with clinical knowledge through repeated application during encounters with patients. With further clinical experience, this organised clinical knowledge matures into prototypes of previously encountered patients, known as illness scripts, which contain little or no explicit bioscience. ${ }^{9}$ In other words, as students become more experienced, their reasoning becomes more like that of an expert clinician. Bioscience knowledge structures are subsumed into clinical knowledge, allowing the use of pattern recognition to make shortcuts in diagnostic reasoning by viewing symptoms and signs as integrated wholes rather than individual features. This model also explains why there is very little mention of basic science principles or mechanisms in explicit recall of diagnostic reasoning by expert clinicians. ${ }^{12}$

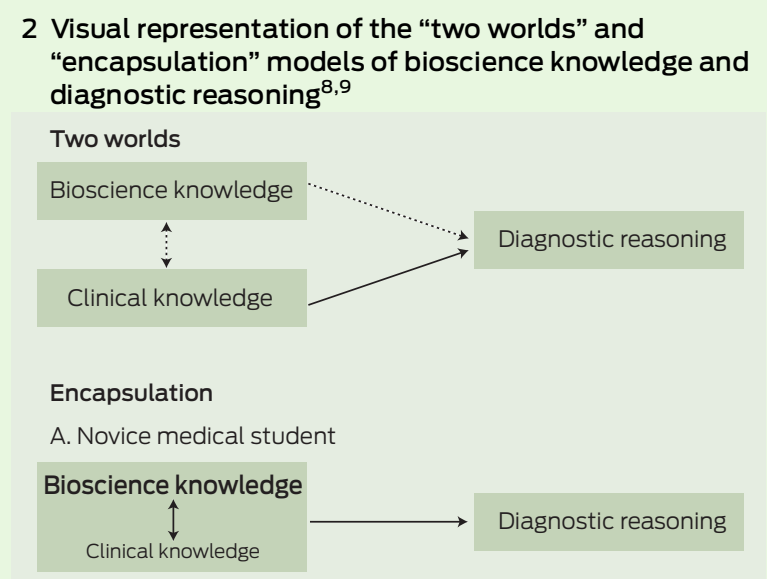

B. Experienced clinician

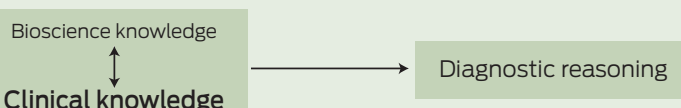




\section{Comparison of two potential learning mechanisms to attain clinical competence}

Integrated bioscience and clinical knowledge

Clinical features learnt in the context of an understanding of the pathophysiology and causal mechanisms of the disease

\section{Learn causes of osteoarthritis}

- Genetic, overweight, injury, inflammation, bone disease

Learn pathophysiology of osteoarthritis

A. Abnormal forces on normal cartilage

- eg, cartilage surface irregularities; malalignment of the joint; loss of ligamentous stability; loss of protective sensory feedback; other causes (eg, obesity, occupation)

B. Normal forces on abnormal cartilage

- eg, pre-existing arthritis; metabolic abnormalities; genetic

C. Normal forces on normal cartilage supported by stiffened subchondral bone

- eg, Paget disease

D. Normal forces on normal cartilage supported by weakened subchondral bone

- eg, avascular necrosis

Learn clinical features of osteoarthritis

- Joint pain in specific joints, stiffness and/or tenderness; limited range of motion; crepitus; joint effusion; bony enlargements (osteophytes)

\section{Clinical knowledge only}

Learning mechanism

Clinical features of disease learnt

\section{Example: Osteoarthritis}

\section{Learn pattern of joint involvement in osteoarthritis}

- Axial: cervical and lumbar spine

- Peripheral: distal interphalangeal joint, proximal interphalangeal joint, first carpometacarpal joints, knees, hips and first metatarsophalangeal joint

Learn symptoms

- Joint pain

- Morning stiffness lasting $<30$ minutes

- Joint instability or buckling

- Loss of function

\section{Learn signs}

- Bony enlargement at affected joints

- Limitation of range of motion

- Crepitus on motion

- Pain with motion

- Malalignment and/or joint deformity
A series of studies provide support for the encapsulation model ${ }^{13-15}$ Medical students were instructed about patients with neurological and rheumatological conditions, using basic science explanations, or symptom probabilities or epidemiological information. ${ }^{13,14}$ The students' diagnostic performance was tested immediately after the intervention and again a week later. The students taught using bioscience explanations performed better in the test after 1 week than those taught using symptom probabilities or epidemiological information alone. Box 3 gives an example of two potential learning mechanisms (with and without integrated bioscience) applied to osteoarthritis.

In the third study, medical students were taught about four fictitious diseases, using either causal explanations or symptom lists, and were then tested on their knowledge. ${ }^{15}$ The students exposed to causal learning again outperformed those taught with symptom lists alone, offering further support for the hypothesis that diagnostic competence may be facilitated by encapsulation of bioscience knowledge into clinical material.

\section{Evidence-based practice}

Several authors have proposed that bioscience teaching and learning develops skills for evidence-based practice. ${ }^{1,16,17}$ While there is currently no evidence to directly support this, it makes intuitive sense that developing and applying core evidence-based practice skills - formulating a clinical question and integrating information into clinical practice - needs a solid foundation of bioscience knowledge. Knowledge of anatomy, pathology, pharmacology and immunology allows clinicians to appraise the relevance and applicability of research evidence to a particular clinical scenario, and to develop an organisational framework, so that appropriate comparisons and choices can be made and justified. For example, understanding how pharmacological agents compensate for pathophysiological mechanisms of disease allows clinicians to develop a systematic and rational approach to drug therapy.

\section{The clinician-scientist}

Another argument for providing medical students with the opportunity to study biosciences is that the excitement of discovery will increase their likelihood of becoming involved in research in the future. This premise was accepted by those who trained medical students in 19th century Germany. ${ }^{18}$ Support for this argument comes from those who see advances in medical care as being derived from curiosity-driven science, rather than the pursuit of science to achieve particular clinical outcomes. ${ }^{1,19}$ The reduced amount of bioscience teaching and learning in medical programs has been blamed for the declining numbers of clinician-scientists worldwide, although it is acknowledged that multiple factors are contributing to this situation..$^{20}$

\section{Which is the most effective bioscience education model?}

\section{The Flexnerian model}

Although the Flexner report improved scientific rigour in medical school programs, it promoted a curriculum that separated bioscience learning from clinical learning and divided the biosciences into individual disciplines, the epitome of the two-worlds model. Moreover, the conventional Flexnerian instruction model was based on imparting knowledge through lectures and other didactic teaching. Given that emerging evidence supports the encapsulation model, a Flexner curriculum may not be the most effective way of developing clinical expertise from bioscience knowledge. 


\section{Problem-based learning}

The introduction of PBL has substantially changed how medical programs deliver bioscience teaching and learning. In PBL, the integration of bioscience and clinical learning is combined with a constructivist approach proposing that students learn best by building their own knowledge within clinical contexts. All Australian medical schools apply PBL to the preclinical and, in some cases, the clinical phases of their programs. Published research suggests that PBL is preferred over conventional course learning by both students and teachers. This is because, unlike purely didactic teaching, it provides a clinical context for learning and more effectively develops students' diagnostic reasoning skills. ${ }^{21-23}$

However, several authors have suggested that the amount of bioscience knowledge students gain from PBL programs is less than that of their colleagues from conventional courses. ${ }^{24-26}$ The AMES survey of medical students, recent graduates, employers and clinical trainers noted, when highlighting concerns about the breadth and depth of student bioscience knowledge, that use of PBL "... encourages hypothesis generation which may not be based on fact ..."27 Balanced against the substantial resources required for its implementation, PBL may not have much advantage over conventional courses for bioscience learning, particularly once students have entered the professional workforce. Variations, such as case-based, community-based or computer-assisted learning, have been applied at some medical schools, but there is little evidence as yet to determine whether these methods are superior to conventional PBL.

\section{Bioscience in the clinical years}

A more recent approach to using bioscience learning to develop clinical expertise has been the delivery of bioscience courses in the clinical years of medical programs. Of 127 US and 17 Canadian medical schools surveyed, $19 \%$ of the US schools and $24 \%$ of the Canadian schools offered bioscience courses in the clinical years. ${ }^{28}$ As an example, at the University of Pittsburgh School of Medicine (Pittsburgh, USA), the following integrated life-science courses are offered in the clinical years: neoplastic disease, clinical pharmacology, infectious disease, surgery integrated life sciences, molecular medicine and the science of resuscitation. Similar programs have been implemented at medical schools elsewhere in the world, but evidence of the effectiveness of promoting bioscience integration on outcomes such as improved diagnostic reasoning is inconclusive. ${ }^{28}$

\section{Conclusion}

The evidence we present, although not definitive, supports a substantial role for bioscience learning in the development of clinical competence, in particular for diagnostic reasoning skills and specific clinical expertise. Published research also supports the provision of bioscience learning in a clinical context to enhance retention and assist with the transition to professional practice. Thus, the divide between university-based preclinical bioscience learning and subsequent clinical learning in hospital settings, as advocated by
Flexner, and the traditional structure of medical schools worldwide, would seem inappropriate. Instead, increased interaction between the preclinical and clinical stages of medical training, with the breadth and depth of bioscience learning determined by current and future clinical requirements, would appear to be a better pedagogical model. This approach supports case-based learning and PBL, but further reinforcement of bioscience principles in the clinical years would consolidate this knowledge and place it within a diagnostic context. The current trend to integrate bioscience and clinical education is, therefore, to be encouraged, but evaluation of such programs will ensure greater certainty about the role of bioscience and determine the success of any educational intervention.

\section{Competing interests: No relevant disclosures.}

Provenance: Commissioned; externally peer reviewed.

1 Weatherall D. Science in the undergraduate curriculum during the 20th century. Med Educ 2006; 40: 195-201.

2 Finnerty EP, Chauvin S, Bonaminio G, et al. Flexner revisited: the role and value of the basic sciences in medical education. Acad Med 2010; 85: 349-355.

3 Flexner A. Medical education in the United States and Canada: a report to the Carnegie Foundation for the Advancement of Teaching. Boston: Updyke, 1910. (Carnegie Foundation Bulletin No. 4.) http:// www.carnegiefoundation.org/sites/default/files/elibrary/Carnegie_Flexner_Report.pdf (accessed Jan 2012).

4 Australian Medical Education Study. What makes for success in medical education? Synthesis report. Canberra: Department of Education, Employment and Workplace Relations, 2008. http://www.deewr.gov.au/ HigherEducation/Publications/HEReports/Documents/SynthesisReport.pdf (accessed Jan 2012).

5 Baghdady MT, Pharoah MJ, Regehr G, et al. The role of basic science in diagnostic oral radiology. J Dent Educ 2009;73: $1187-1193$.

6 Collins JP, Gough IR. An academy of surgical educators: sustaining education - enhancing innovation and scholarship. ANZ J Surg 2010; 80:13-17.

7 Association of American Medical Colleges, Howard Hughes Medical Institute. Scientific Foundations for Future Physicians. Washington DC, AMMC-HHMl, 2009. http://www.hhmi.org/grants/pdf/08-209_AAMC-HHMl_report.pdf (accessed Jan 2012).

8 Patel VL, Kaufman DR. Clinical reasoning and biomedical knowledge: implications for teaching. In: Higgs J, Jones M, editors. Clinical reasoning in the health professions. Sydney: Butterworth-Heinemann Ltd, 1995: 117-128.

9 Schmidt HG, Norman GR, Boshuizen HP. A cognitive perspective on medical expertise: theory and implications. Acad Med 1990; 65: 611-621.

10 Patel VL, Evans DA, Groen GJ. Biomedical knowledge and clinical reasoning. In: Evans DA, Patel VL, editors. Cognitive sciences in medicine: biomedical modeling. Cambridge, Mass: MIT Press, 1989: 53-112.

11 Patel VL, Evans DA, Groen GJ. Reconciling basic science and clinical reasoning. Teach Learn Med 1989; 1: 116-121.

12 Rikers RM, Schmidt HG, Moulaert V. Biomedical knowledge: encapsulated or two worlds apart? Appl Cogn Psychol 2005; 19: 223-231.

13 Woods NN, Brooks LR, Norman GR. The value of basic science in clinical diagnosis: creating coherence among signs and symptoms. Med Educ 2005; 39: 107-112.

14 Woods NN, Brooks L, Norman GR. The role of biomedical knowledge in diagnosis of difficult cases. Adv Health Sci Educ Theory Pract 2007; 12: 417-426.

15 Woods NN, Brooks LR, Norman GR. It all make sense: biomedical knowledge, causal connections and memory in the novice diagnostician. Adv Health Sci Educ Theory Pract 2007; 12: 405-415.

16 Sweeney G. The challenge for basic science education in problem-based medical curricula. Clin Invest Med 1999; 22: $15-22$.

17 Grande JP. Training the physicians for the twenty-first century: role of the basic sciences. Med Teach 2009; 31: $802-$ 806.

18 Bligh J. Learning about science is still important [comment]. Med Educ 2003; 37: 944-945.

19 Comroe JH Jr, Dripps RD. Scientific basis for the support of biomedical science. Science 1976; 192: 105-111.

20 Zemlo TR, Garrison HH, Partridge NC, Ley TJ. The physician-scientist: career issues and challenges at the year 2000. FASEB J 2000; 14:221-230

21 Schmidt HG, Machiels-Bongaerts M, Hermans H, et al. The development of diagnostic competence: comparison of a problem-based, an integrated, and a conventional medical curriculum. Acad Med 1996; 71: 658-664.

22 Hmelo CE. Cognitive consequences of problem-based learning for the early development of medical expertise. Teach Learn Med 1998; 10: 92-100.

23 Kaufman DM, Mann KV. Comparing achievement on the Medical Council of Canada Qualifying Examination Part I of students in conventional and problem-based learning curricula [comment in Acad Med 1999; 74: 852-853]. Acad Med 1998; 73: 1211-1213.

24 Albanese MA, Mitchell S. Problem-based learning: a review of literature on its outcomes and implementation issues [comment in Acad Med 1993; 68:545; erratum in Acad Med 1993; 68: 615]. Acad Med 1993; 68: 52-81.

25 Berkson L. Problem-based learning: have the expectations been met? [comment in Acad Med 1994; 69: 471-472, author reply 473-474; comment inAcad Med 1994; 69: 472-473, author reply 473-474].Acad Med 1993; 68 (10 Suppl) S79-S88.

26 Vernon DT, Blake RL. Does problem-based learning work? A meta-analysis of evaluative research. Acad Med 1993; 68:550-563.

27 Lawson M, Bearman M, Byrne C. Survey report: medical students, recent medical graduates, employers and clinical trainers. Australian Medical Education Study. Canberra: Australian Government Department of Education, Science and Training, 2007. http://www.deewr.gov.au/HigherEducation/Publications/HEReports/Documents/AMES-45.pdf (accessed Feb 2012).

28 Spencer AL, Brosenitsch T, Levine AS, Kanter SL. Back to the basic sciences: an innovative approach to teaching senior medical students how best to integrate basic science and clinical medicine. Acad Med 2008; 83: 662-669. 